\title{
Intervention with fish oil, but not with docosahexaenoic acid, results in lower levels of hepatic soluble epoxide hydrolase with time in apoE knockout mice
}

\author{
Yiannis Mavrommatis ${ }^{1}$, Karen Ross ${ }^{1}$, Garry Rucklidge ${ }^{1}$, Martin Reid ${ }^{1}$, Gary Duncan ${ }^{1}$, \\ Margaret-Jane Gordon ${ }^{1}$, Frank Thies ${ }^{1,2}$, Alan Sneddon ${ }^{1}$ and Baukje de Roos ${ }^{1 *}$ \\ ${ }^{1}$ Rowett Institute of Nutrition and Health, University of Aberdeen, Aberdeen AB21 9SB, UK \\ ${ }^{2}$ Department of Medicine and Therapeutics, University of Aberdeen, Aberdeen, UK
}

(Received 7 November 2008 - Revised 3 June 2009 - Accepted 4 June 2009 - First published online 13 August 2009)

Long-chain n-3 PUFA from fish oil protect against death from CHD but mechanisms are not well understood. Preliminary results indicate that fish oil may affect the enzyme soluble epoxide hydrolase $(\mathrm{sEH})$ and influence inflammatory pathways in a time-dependent manner. In the present study male apoE knockout $\left(\right.$ Apoe ${ }^{-1-}$ ) mice were randomised to three dietary groups receiving a high-fat high-cholesterol diet supplemented with $2 \%$ (w/w) high-oleic acid sunflower-seed (HOSF) oil, DHA oil or fish oil. Livers and proximal aortas were collected on day 2 and on weeks 1, 2, 4 and 10 to determine hepatic sEH levels, hepatic fatty acid composition, hepatic proteome and atherosclerotic plaque size in the aortic root. Intervention with fish oil, but not with DHA, resulted in significantly lower levels of hepatic sEH levels with time compared with HOSF oil. DHA and fish oil caused differential regulation of thirty-five hepatic proteins which were mainly involved in lipoprotein metabolism and oxidative stress. All mice developed atherosclerosis without differences in plaque size between the three groups. Thus EPA may be responsible for lowering levels of hepatic sEH and both fish oil and DHA could beneficially affect lipoprotein metabolism and oxidative stress.

Epoxyeicosatrienoic acids: $n-3$ Fatty acids: Proteomics: Atherosclerosis

Epidemiological studies have suggested that consumption of long-chain $n$-3 PUFA protects against CHD and may lower risk of CHD mortality by approximately $40 \%^{(1-3)}$. Intervention studies on secondary prevention also indicate protective effects of fish oil consumption on total cardiac events and a decrease in sudden death at a relatively low level of fish oil intake (i.e. $1 \mathrm{~g} / \mathrm{d})^{(4)}$. Long-chain $n$-3 PUFA are found in high concentrations in oily fish and the oils derived from them. The mechanisms through which long-chain $n-3$ PUFA affect CVD are not fully understood but include a decrease in fasting and postprandial TAG, a decrease in arrhythmias, modulation of platelet aggregation, decreased synthesis of pro-inflammatory agents and increased atherosclerotic plaque stability ${ }^{(5,6)}$. These favourable effects could be attributed to the longchain $n$-3 PUFA EPA, the main long-chain $n$-3 PUFA in fish oil. However, controlled studies in human subjects now demonstrate that the long-chain $n-3$ PUFA DHA has equally important anti-arrhythmic, anti-thrombotic and anti-atherogenic effects, although it is often present in lower amounts in oily fish and fish oil supplements ${ }^{(7,8)}$.

Preliminary data indicate that dietary fish oil may also affect levels of the enzyme soluble epoxide hydrolase $(\mathrm{sEH})^{(9)}$. Regulation of this enzyme could affect the availability and metabolism of epoxyeicosatrienoic acids (EET). EET are synthesised from the oxygenation of arachidonic acid by cytochrome P450 NADPH-dependent epoxygenases; there are four regio-isomers of EET: 5,6-, 8,9-, 11,12- and $14,15-\mathrm{EET}^{(10)}$. EET possess a number of properties associated with cardiovascular health. For example, EET inhibit expression of adhesion molecules (vascular cell adhesion molecule-1, intercellular adhesion molecule-1 and E-selectin) through an NF-кB-related mechanism ${ }^{(11)}$. Additionally, EET are potential candidates for endothelium-derived hyperpolarising factors producing vasorelaxation and lower blood pressure $^{(12,13)}$. Also, EET play an important role in maintaining fibrinolytic stability in blood vessels ${ }^{(14)}$. $\mathrm{sEH}$ is responsible for the hydrolysis of the bioactive EET to the less biologically active dihydroxyeicosatrienoic acids ${ }^{(15)}$. Therefore, regulation of sEH by fish oil could affect EET levels, thereby affecting inflammation, vasorelaxation, blood pressure, fibrinolytic stability, and eventually atherosclerosis development. Such effects may be mediated through EPA, DHA or both. In the present study, we investigated the in vivo effects of dietary DHA or fish oil (EPA plus DHA) on hepatic sEH gene expression and protein levels in Apoe $e^{-/-}$mice with time. In addition, we also assessed the effects of DHA and fish oil on atherosclerotic plaque size and on the hepatic proteome to elucidate potential mechanisms of action that may be, directly or indirectly, related to the development of atherosclerosis. Proteomics have revealed differential regulation of catalase

Abbreviations: 2D, two-dimensional; EET, epoxyeicosatrienoic acid; FOXO3a, forkhead box transcription factor 3a; HFC, high-fat high-cholesterol; HOSF, high-oleic acid sunflower-seed; sEH, soluble epoxide hydrolase.

* Corresponding author: Dr Baukje de Roos, fax +44 1224 716629, email b.deroos@abdn.ac.uk 
and peroxiredoxin 3 , which are proteins with an important role in oxidative stress and atherogenesis that may be regulated via the forkhead box transcription factor (FOXO3a) ${ }^{(16)}$, which in turn can be inactivated by $\mathrm{EET}^{(17)}$. Therefore, we also determined hepatic gene expression of FOXO3a, as well as relative protein levels of hepatic superoxide dismutase and catalase in the present study.

\section{Materials and methods}

The study protocol was approved by the Ethical Review Committee of Animal Studies at the Rowett Research Institute, and was conducted in compliance with the Animals (Scientific Procedures) Act, 1986.

\section{Animals and diets}

Seventy-five male Apoe $e^{-1-}$ mice, aged 4 weeks, were caged individually under standard conditions with free access to diet and water. All mice were fed a high-fat $(16 \%$, w/w) highcholesterol $(0.25 \%$, w/w) diet (HFC diet; Arie Block BV, Woerden, The Netherlands) supplemented with $2 \%(\mathrm{w} / \mathrm{w})$ high-oleic acid sunflower-seed (HOSF) oil (Lipid Nutrition, Wormerveer, The Netherlands) for a run-in period of 2 weeks. The mice were then randomised to three intervention groups of twenty-five mice each that were matched for weight. Mice in the first group (control group) continued to consume the HFC diet supplemented with $2 \%$ (w/w) HOSF oil. Mice in the second group started to consume the HFC diet supplemented with $2 \%(\mathrm{w} / \mathrm{w})$ DHA oil containing $40 \%$ DHA and no EPA (DHA Neuromins ${ }^{\circledR}$; Martek, Columbia, MD, USA). Mice in the third group started to consume the HFC diet supplemented with $2 \%(\mathrm{w} / \mathrm{w})$ fish oil, containing $22 \%$ EPA and $17 \%$ DHA (Marinol ${ }^{\mathrm{TM}}$ C-38; Lipid Nutrition). Fish oil rather then EPA was used because of the unavailability of pure EPA. All intervention oils were matched for added antioxidants including vitamin $\mathrm{E}$. The energy provided by DHA in the DHA group, or by EPA + DHA in the fish oil group, was $1.6 \%$, which is equivalent to $3-4 \mathrm{~g} / \mathrm{d}$ in humans based on metabolic intake. All three diets had a similar fat and energy content (Table 1). The diets were freeze-dried and stored under $\mathrm{N}_{2}$ at $-80^{\circ} \mathrm{C}$ until use. Adequate portions of the diets for ad libitum intake were given to the mice every other day. Food intakes were recorded three times per week and mice were weighed twice per week. Five mice per

Table 1. Fatty acid composition of the three diets*

\begin{tabular}{lccc}
\hline Fatty acid (g/100 g diet) & HOSF oil diet & DHA diet & Fish oil diet \\
\hline SFA & 9.02 & 9.54 & 9.60 \\
MUFA & 6.17 & 5.19 & 5.07 \\
Oleic acid & 6.12 & 5.12 & 4.96 \\
PUFA & 1.08 & 1.63 & 1.63 \\
$n$-6 PUFA & 1.06 & 0.91 & 0.94 \\
$n-3$ PUFA & 0.02 & 0.72 & 0.69 \\
$\quad$ EPA & 0.0 & 0.0 & 0.38 \\
DHA & 0.0 & 0.69 & 0.27 \\
\hline
\end{tabular}

HOSF, high-oleic acid sunflower-seed.

* The fatty acid composition of the experimental diets was analysed as described in the Materials and methods section. In addition to the fat, all diets contained $0.25 \%$ cholesterol, $40.5 \%$ sucrose, $10 \%$ maize starch, $5.95 \%$ cellulose, $20 \%$ casein, $1 \%$ choline chloride, $0.2 \%$ methionine and $5.1 \%$ mineral mixture. group were killed by terminal anaesthesia with isofluorane followed by cardiac puncture to collect blood after $2 \mathrm{~d}$ and $1,2,4$ and 10 weeks of dietary intervention. Livers and hearts plus the proximal part of the aorta were also collected at each time-point. Hearts and proximal aortas were flushed with sterile PBS and snap-frozen in $\mathrm{OCT}^{\mathrm{TM}}$ compound using liquid $\mathrm{N}_{2}$. Livers were also snap-frozen in liquid $\mathrm{N}_{2}$. Both tissues were stored at $-80^{\circ} \mathrm{C}$.

\section{Lipid content and fatty acid composition of intervention diets and animal livers}

Total lipids were extracted from three samples per intervention diet. Total lipids were also extracted from the livers of three mice per group after $2 \mathrm{~d}$ and 10 weeks. Lipids were extracted by the Folch method ${ }^{(18)}$ and converted to methyl esters using acid-catalysed transesterification with sulfuric acid ( $1 \%$ in methanol) at $50^{\circ} \mathrm{C}$ overnight. Heptadecaenoic acid (1/10th the weight of the total lipids) was used as the internal standard. Methyl esters were purified on silicic acid columns, re-dissolved in isohexane to a concentration of $5 \mathrm{mg} / \mathrm{ml}$ and analysed by GC using an Agilent $6890 \mathrm{GC}$ system (Agilent Technologies UK Ltd, Stockport, UK) fitted with a flame ionisation detector. A quantity of $1 \mu \mathrm{l}$ of sample was injected onto a split inlet (20:1 split ratio) set at $250^{\circ} \mathrm{C}$ at a pressure of 25 pounds per square inch (psi) and a split flow of $46.9 \mathrm{ml} / \mathrm{min}$. The initial oven temperature was $80^{\circ} \mathrm{C}$, then increasing at a rate of $25^{\circ} \mathrm{C} / \mathrm{min}$ to $180^{\circ} \mathrm{C}$, then at $1^{\circ} \mathrm{C} / \mathrm{min}$ to $220^{\circ} \mathrm{C}$. A $30 \mathrm{~m} \mathrm{DB} 23$ column (Jones Chromatography, Hengoed, Mid Glamorgan, UK) was used with $\mathrm{He}$ as the carrier gas. The flame ionisation detector was set at $250^{\circ} \mathrm{C}$ with a $\mathrm{H}_{2}$ flow rate of $40.0 \mathrm{ml} / \mathrm{min}$, an air flow of $450 \mathrm{ml} / \mathrm{min}$ and the make-up gas $\left(\mathrm{N}_{2}\right)$ was set at $45 \mathrm{ml} / \mathrm{min}$. Total run time was $44 \mathrm{~min}$. The GC was calibrated for identification of fatty acids using Supelco 37 Component FAME mix (Sigma, St Louis, MO, USA).

\section{Proteomics analysis}

Cytosolic protein homogenates were prepared from each individual animal liver as described previously $(9,19,20)$. The homogenates were separated by two-dimensional (2D) gel electrophoresis using Bio-Rad immobilised $\mathrm{pH}$ gradient

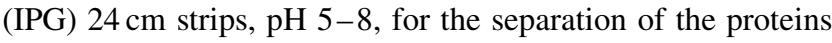
in the first dimension. Gels were analysed using PDQuest software (Bio-Rad, Hercules, CA, USA) as described ${ }^{(9,19,20)}$. Spots with densities that significantly differed between treatments were excised from the SDS-PAGE gels using a robotic Bio-Rad spot cutter. The proteins represented by these spots were trypsinised using a protocol of the Micromass MassPrep Station (Micromass Ltd, Manchester, UK) and analysed by electrospray LC-MS methods as described previously $^{(9,19-21)}$.

\section{Western blots}

Liver protein homogenates and pre-stained protein markers (Precision Plus Protein Standards; Bio-Rad) were separated by SDS-PAGE and blotted onto a polyvinylidene difluoride membrane (Immobilon $\mathrm{P}^{\mathrm{TM}}$; Millipore, Bedford, MA, USA). Random samples from all dietary groups and time-points 
were run on the same gel. Membranes were blocked using $5 \%$ non-fat dried milk in Tris-buffered saline-Tween-20 (TBST; $15 \mathrm{~mm}$-2-amino-2-hydroxymethyl-propane-1,3-diol- $\mathrm{HCl}, \quad \mathrm{pH}$ $7 \cdot 6,150 \mathrm{mM}-\mathrm{NaCl}$ and $0.005 \%$ Tween 20 ) for $1 \mathrm{~h}$, and then incubated with either rabbit anti-sEH polyclonal antibody (generously provided by B. Hammock) (1:10000), or rabbit anti-NF-кBp65 and $\mathrm{I} \kappa \mathrm{B} \alpha$ polyclonal antibodies (Santa Cruz Biotechnology, Santa Cruz, CA, USA; both 1:500), or rabbit anti-catalase polyclonal antibody (Abcam plc, Cambridge, Cambs, UK) (1:1000), or rabbit anti-mitochondrial superoxide dismutase polyclonal antibody (Abcam plc) (1:5000), or rabbit anti-peroxiredoxin 3 (1:10000; LabFrontier Ltd, Seoul, South Korea) for $1 \mathrm{~h}$. Subsequently, membranes were incubated with goat anti-rabbit antibody conjugated to horseradish peroxidase $(1: 20000)$ for $30 \mathrm{~min}$. Membranes were washed with TBST and antibody labelling was detected by enhanced chemiluminescence. Band intensity was measured densitometrically using AIDA image analysis software (Raytek Scientific Ltd, Sheffield, UK).

To validate the identity of $\mathrm{sEH}$ and peroxiredoxin 3 proteins on the 2D gel, four 2D gels of a hepatic protein homogenate were run as described above. Two of these gels were stained with Coomasie blue and the other two were blotted with either a rabbit anti-sEH antibody or rabbit antiperoxiredoxin 3 antibody as described above. The proteins were visualised, excised and identified using LC-MS/MS as described above.

\section{Semi-quantitative RT-PCR}

Frozen liver tissue was homogenised in $\mathrm{QIAzol}^{\mathrm{TM}}$ lysis reagent $(1 \mathrm{ml} / 100 \mathrm{mg}$ tissue) according to the manufacturer's instructions using an Ultra-Turrax homogeniser. Extracted RNA was quantified by spectrophotometric Nanodrop (ND-1000; Nyxor Biotech, Paris, France) and the quality was assessed by gel electrophoresis.

cDNA was synthesised using a Reverse-IT ${ }^{\mathrm{TM}}$ 1st Strand Synthesis Kit (ABgene, Epsom, Surrey, UK) according to the manufacturer's instructions using $1 \mathrm{mg}$ RNA. Secondary structure was removed by heating at $70^{\circ} \mathrm{C}$ for $5 \mathrm{~min}$, first-strand synthesis was carried out at $47^{\circ} \mathrm{C}$ for $50 \mathrm{~min}$ and inactivation by Reverse-iT RTase Blend at $75^{\circ} \mathrm{C}$ for $10 \mathrm{~min}$.

Semi-quantitative RT-PCR was performed using a Taq DNA polymerase kit (Qiagen, Crawley, West Sussex, UK). The reaction mixture $(23 \mu \mathrm{l})$ contained $2.5 \mu \mathrm{l}$ CoralLoad
PCR buffer $10 \times, 5 \mu \mathrm{l}$ Q solution $(5 \times), 2.0 \mu \mathrm{l}$ of dNTPs $\left(2.5 \mu \mathrm{M}\right.$ each), $2.5 \mu \mathrm{l}$ of primers $(10 \mu \mathrm{M}), 1.5 \mu \mathrm{l} \mathrm{MgCl}_{2}$ (25 mM), $0.12 \mu \mathrm{l}(0.6 \mathrm{U})$ of $\mathrm{Taq}$ polymerase and $9.4 \mu \mathrm{l}$ nuclease-free water. The mixture was then added to $2 \mu \mathrm{l}$ of cDNA. Settings of the thermal cycler (Px2 thermal cycler; Thermo, Milford, MA, USA) were $94^{\circ} \mathrm{C}$ for $45 \mathrm{~s}, 50-58^{\circ} \mathrm{C}$ (depending on primers) for $45 \mathrm{~s}$, and $72^{\circ} \mathrm{C}$ for $45 \mathrm{~s}$ and were repeated twenty-five to thirty-five times (depending on gene). Amplified products were separated by electrophoresis in a $3 \%$ agarose gel in TAE buffer ( $40 \mathrm{~mm}$-2-amino-2-hydroxymethyl-propane-1,3-diol, $20 \mathrm{~mm}$-acetic acid, $2 \mathrm{mM}$-EDTA). The PCR products were stained with $0.1 \%$ ethidium bromide, photographed in a UV camera and the images were analysed using AIDA image analysis software (Raytek Scientific Ltd, Sheffield, UK). Glyceraldehyde-3-phosphate dehydrogenase mRNA levels were used to normalise the mRNA levels of the genes of interest. The gene names, primer sequences and number of cycles for each gene are shown in Table 2 . RT-PCR for $\mathrm{sEH}$ was performed with liver samples from all time-points whereas for FOXO3a only samples from the first (day 2) and last (week 10) time-points were used.

\section{Measurement of atherosclerotic plaque size}

A modified version of the Paigen method was used for the measurement of plaque size at the aortic $\operatorname{root}^{(22)}$. The proximal aorta was sectioned perpendicularly to the aortic axis in a direction from the aortic arch towards the centre of the heart using a cryostat (Leica CM 1850; Leica Microsystems, Nussloch, Germany). Some $8 \mu \mathrm{m}$ sections were taken, air-dried for $1 \mathrm{~h}$ and rinsed briefly in $60 \%$ isopropyl alcohol. Sections were stained with Sudan IV, counterstained with Harris haematoxylin and photographed with a digital camera (Hamamatsu colour chilled 3ccd camera; Hamamatsu Photonics UK Ltd, Welwyn Garden City, Herts, UK). Plaque area was measured by computer-assisted image analysis software (Image Pro Plus version 4.5 for Windows; Media Cybergenetics, Marlow, Bucks, UK).

\section{Statistics}

For Western blots and RT-PCR experiments, randomised samples including all dietary groups and time-points were run on the same gel to control for between-gel variation. Results were analysed using two-way ANOVA to assess

Table 2. Genes, sense and antisense primers, product size and number of cycles used for performing RT-PCR for each gene

\begin{tabular}{llcc}
\hline Gene & & Product size (bp) & No. of cycles \\
\hline $\begin{array}{l}\text { Gapdh } \\
\text { Sense primer }\end{array}$ & GTGGAGATTGTTGCCATCAA & 241 & 30 \\
$\begin{array}{l}\text { Antisense primer } \\
\text { Ephx2 }\end{array}$ & CCTTCTCCATGGTGGTGA & 417 & 35 \\
$\quad$ Sense primer & CCTGATGTGTCTCCCATGAAAG & & \\
$\quad$ Antisense primer & GGACATTTCAGGACGGAGTACA & \multirow{2}{*}{30} \\
$\begin{array}{l}\text { Foxo3a } \\
\text { Sense primer }\end{array}$ & ACGACGATGAAGACGACGAGGA & & \\
Antisense primer & TTGCTCCACCACCAGCACCAAA & & \\
\hline
\end{tabular}

Gapdh, glyceraldehyde-3-phosphate dehydrogenase; Ephx2, epoxide hydrolase 2; Foxo3a, forkhead box transcription factor $3 a$. 
differences between the three different groups, the five time points, and the interaction between treatments and time points. For the proteomics data, two-way ANOVA was also used for trends in time. Analyses were performed using Genstat (ed. 10.0.1.71; Rothamsted Experimental Station, Harpenden, Herts, UK). Data are presented as mean values with their standard errors.

\section{Results}

\section{Food intake and body-weight gain}

There were no differences in food intake and body-weight gain between the three groups during the intervention period (data not shown).

\section{Hepatic lipid levels and fatty acid composition}

Hepatic lipid levels and hepatic weight did not differ between the three intervention groups during the 10 -week intervention period (data not shown). Consumption of the DHA-rich diet caused a very rapid (i.e. within $2 \mathrm{~d}$ ) incorporation of DHA in the pool of hepatic fatty acids, partly at the cost of arachidonic acid. Consumption of fish oil also caused a rapid incorporation of DHA, and a slower incorporation of EPA, in the pool of hepatic fatty acids, partly at the cost of arachidonic acid. DHA was present in significantly higher concentrations than EPA at day 2 and week 10 $(P<0.05$; Fig. 1).

Hepatic proteomics, soluble epoxide hydrolase protein levels and soluble epoxide hydrolase gene expression

Proteomics analysis revealed thirty-five cytosolic proteins, which were significantly up-regulated or down-regulated by DHA or fish oil compared with the control group (Table 3). In addition, levels of four proteins were significantly different between the DHA and fish oil groups with time. Differentially regulated proteins were identified by LC-MS/MS and categorised based on their main functions (Table 3). Proteomics revealed, amongst other changes, that both the DHA and fish oil interventions decreased one isoform of hepatic apoA1 with time $(P<0 \cdot 05)$. In addition, in the fish oil, but not in the DHA group, hepatic sEH protein levels were lower $(P<0.05)$ compared with the control group with time. The lower sEH levels in the fish oil group resulted from the prevention of an increase that occurred in the DHA and the control groups rather than a decrease in hepatic levels of sEH (Table 3, Fig. 2(a)). Positive identification of the sEH protein on the $2 \mathrm{D}$ gels was confirmed by probing the 2D gel with polyclonal sEH antibody followed by excision and analysis of the positive spot from the Coomasie-stained gel by LC-MS/MS. We did not observe similar differences in hepatic sEH protein levels with time upon DHA and fish oil intervention, as compared with HOSF oil intervention, using Western blot analysis (Fig. 2(b)). DHA and fish oil interventions, as compared with the HOSF oil intervention, did not affect hepatic sEH gene expression (Fig. 2(c)). In addition, both fish oil and DHA down-regulated hepatic phenylalanine hydroxylase Se-binding protein 2 and glyceraldehyde-3-phosphate dehydrogenase with time, and fish oil down-regulated ketohexokinase and formyltetrahydrofolate dehydrogenase with time.

\section{Regulation via the forkhead box transcription factor FOXO3a}

Proteomic analysis revealed a decrease in hepatic peroxiredoxin 3 protein levels in time by both the fish oil and DHA interventions, compared with the HOSF oil intervention (Table 3). Blotting of the 2D gel with a polyclonal peroxiredoxin 3 antibody, followed by the analysis of the stained single spot by LC-MS/MS, confirmed the identity of the specific protein on the gel as peroxiredoxin 3 .

A previous study in cardiac fibroblasts has shown that gene expression of peroxiredoxin 3 is mediated by FOXO3a ${ }^{(16)}$, which in human umbilical vein endothelial cells is inactivated by $11,12-\mathrm{EET}^{(17)}$. Therefore, we measured hepatic FOXO3a gene expression using semi-quantitative RT-PCR, as well as protein levels of the antioxidant enzymes catalase and superoxide dismutase using Western blot analysis. Both antioxidant

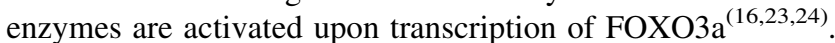
Neither hepatic gene expression of FOXO3a nor hepatic protein levels of mitochondrial superoxide dismutase and catalase were affected by fish oil or DHA intervention (data not shown).

\section{Atherosclerotic plaque measurement}

All treatment groups developed atherosclerotic plaques during the intervention period, but plaque size did not significantly differ between the DHA or fish oil intervention as compared
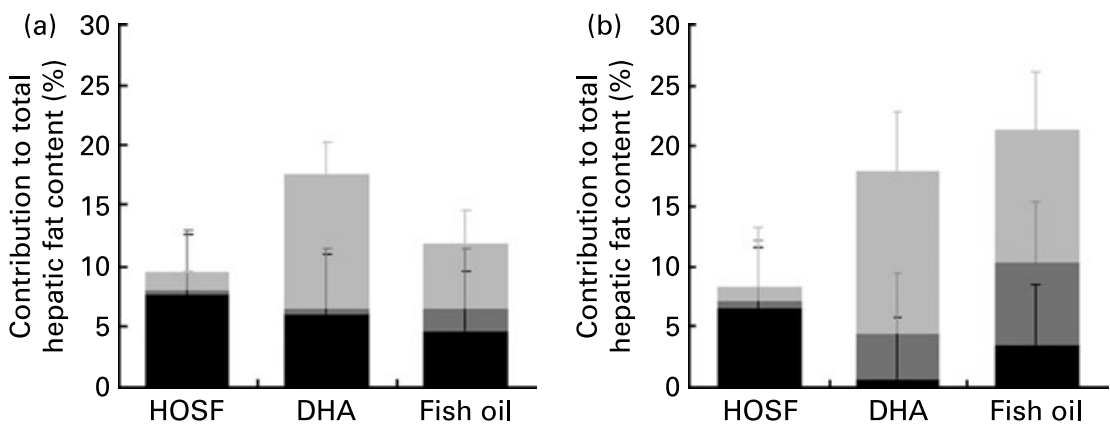

Fig. 1. Contribution of DHA $(\square)$, EPA $(\square)$ and arachidonic acid $(\square)$ to total hepatic fat content (\%) upon dietary intervention with $2 \%$ (w/w) high-oleic acid sunflowerseed (HOSF) oil, $2 \%(w / w)$ DHA and $2 \%(w / w)$ fish oil for $2 d(a)$ and 10 weeks $(b)$. Values are means, with standard errors represented by vertical bars. 
Table 3. Proteins with significantly altered levels upon intervention with DHA or fish oil (FO), compared with high-oleic acid sunflower-seed (HOSF) oil over time* $\dagger$

\begin{tabular}{|c|c|c|c|c|c|c|c|c|c|c|c|}
\hline & \multicolumn{5}{|c|}{$\mathrm{DHA}$} & \multicolumn{5}{|c|}{ FO } & Diet $\times$ time \\
\hline Protein & $2 d$ & $\begin{array}{c}1 \\
\text { week }\end{array}$ & $\begin{array}{c}2 \\
\text { weeks }\end{array}$ & $\begin{array}{c}4 \\
\text { weeks }\end{array}$ & $\begin{array}{c}10 \\
\text { weeks }\end{array}$ & $2 d$ & $\begin{array}{c}1 \\
\text { week }\end{array}$ & $\begin{array}{c}2 \\
\text { weeks }\end{array}$ & $\begin{array}{c}4 \\
\text { weeks }\end{array}$ & $\begin{array}{c}10 \\
\text { weeks }\end{array}$ & DHA \\
\hline
\end{tabular}

Lipid metabolism

ApoA-I

Peroxisomal CoA diphosphatase NUDT7

Dienoyl-CoA isomerase

Protein metabolism

Acyl-peptide hydrolase

Branched-chain ketoacid dehydrogenase E1

Pyridoxal kinase

Ornithine aminotransferase

Phenylalanine hydroxylase

Selenium-binding protein 2

Aldehyde dehydrogenase 9A1

Glutamate dehydrogenase

Glucose metabolism

Ketohexokinase

GAPDH

Fructose 1,6 bisphosphatase

Alpha enolase

Phosphomutase-1

Oxidative stress

HSP60

Peroxiredoxin 3

3-Hydroxyisobutyrate dehydrogenase

Aldehyde dehydrogenase 7A1

Peroxiredoxin 6

3-Hydroxyanthranilic acid dioxygenase

Isovaleryl-CoA dehydrogenase

Aldehyde dehydrogenase 2 (precursor)

Hydroxypyruvate reductase

Methionine metabolism

Methionine adenosyltransferase

Methionine adenosyltransferase

Formyltetrahydrofolate dehydrogenase
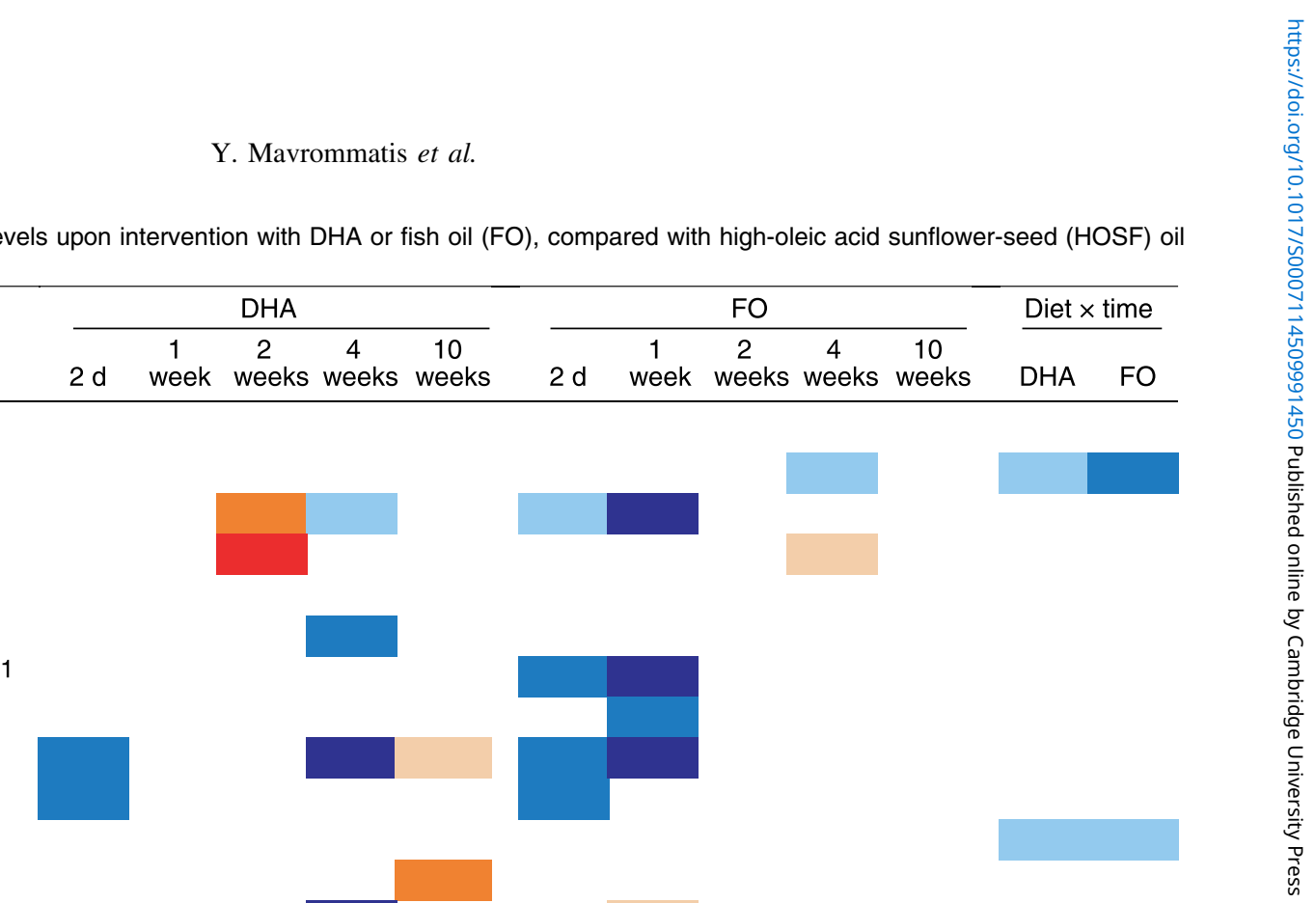

S-adenosylhomocysteine hydrolase

Adenosylhomocysteinase

Other functions

Malate dehydrogenase

Ester hydrolase homologue

Regucalcin

Soluble epoxide hydrolase

Nicotinate nucleotide pyrophosphorylase

GAPDH, glyceraldehyde-3-phosphate dehydrogenase; HSP, heat shock protein.

* $P<0.05$.

$\dagger$ The increase or decrease in protein levels is that compared with the control group (fold change): red, $>2$-fold increase; orange, $>1.5$-fold increase; peach, $>1$-fold increase; light blue, >1-fold decrease; blue, >1.5-fold decrease; dark blue, $>2$-fold decrease.

with the HOSF oil intervention at any time point during the 10 -week period (Fig. 3). The average plaque size after 10 weeks of intervention was 927 (SEM 126), 846 (SEM 56) and 922 (SEM 113) $\mu \mathrm{m}^{2}$ in the control, DHA and fish oil groups, respectively.

\section{Discussion}

The application of proteomics to hepatic tissue in a timecourse design allowed the assessment of short-term and long-term effects of treatment with DHA or fish oil, not only on $\mathrm{sEH}$ regulation but also on other pathways related 
(a)

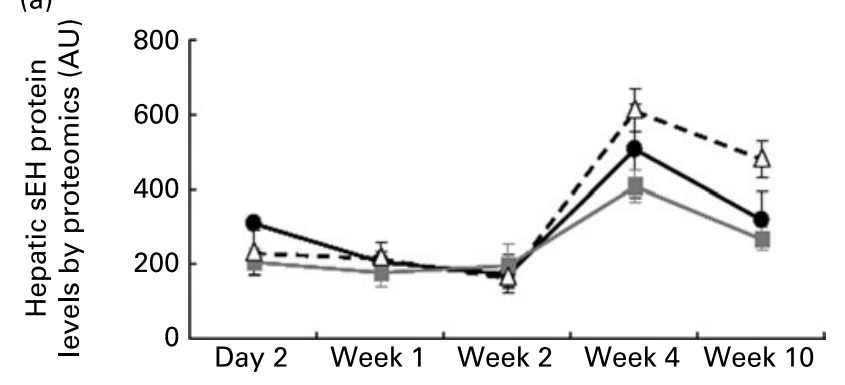

(b)
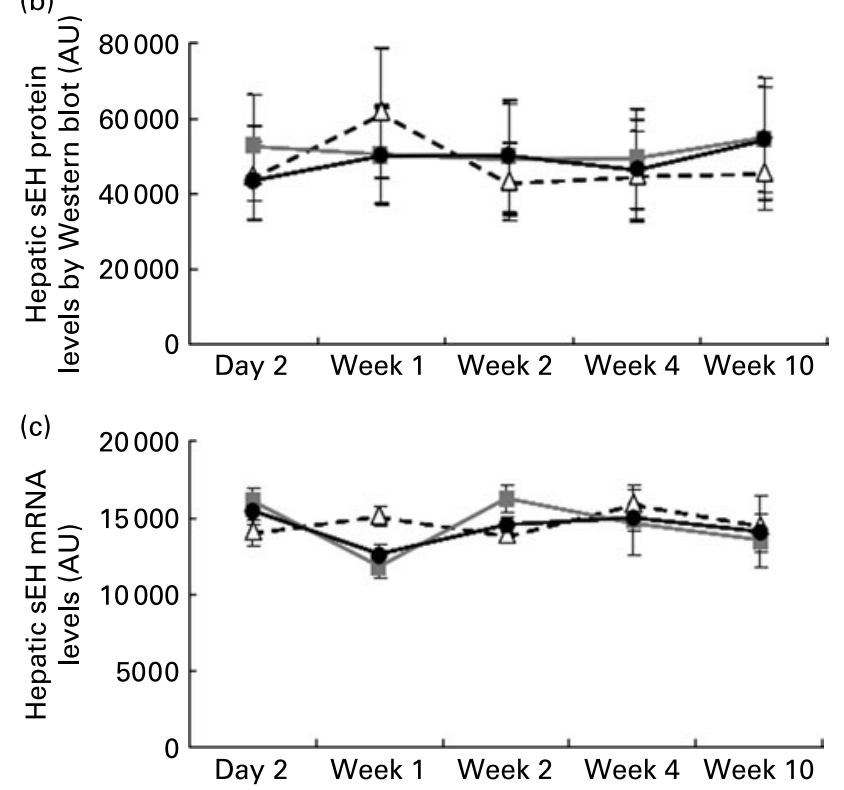

Fig. 2. Hepatic soluble epoxide hydrolase $(\mathrm{sEH})$ protein and gene expression

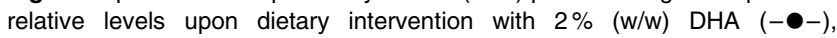
$2 \%(\mathrm{w} / \mathrm{w})$ fish oil $(-\square-)$ or $2 \%(\mathrm{w} / \mathrm{w})$ high-oleic sunflower-seed (HOSF) oil $(--\triangle-)$ for $2 \mathrm{~d}, 1$ week, 2 weeks, 4 weeks and 10 weeks. Values are means for five animals per time point, with standard errors represented by vertical bars. (a) Relative protein levels of hepatic $s E H$ as determined by proteomics. Overall hepatic $\mathrm{sEH}$ levels were significantly lower in the fish oil group compared with the control (HOSF) group $(P<0.05)$. (b) Relative protein levels of hepatic SEH as determined by Western blot and (c) hepatic SEH gene expression as determined by RT-PCR. AU, arbitrary units.

to the development of atherosclerosis, such as lipoprotein metabolism and oxidative stress. Intervention with fish oil, but not with DHA, resulted in significantly lower protein levels of hepatic sEH, whereas intervention with both fish oil and DHA resulted in lower protein levels of hepatic apoA1 and peroxiredoxin 3 with time. Neither fish oil nor DHA affected hepatic gene expression of FOXO3a, or plaque size development as compared with HOSF oil during the 10-week intervention period.

Intervention with either DHA or fish oil resulted in a rapid incorporation of the dietary fatty acids in the hepatic lipid pool (Fig. 1). However, the relatively higher levels of DHA incorporation, as compared with EPA incorporation, in the fish oil group after $2 \mathrm{~d}$ of intervention, despite EPA being present in higher amounts than DHA in the diet (Table 1), suggests a faster initial incorporation of DHA at the cost of arachidonic acid. In the long term (i.e. after 10 weeks of intervention), however, the relative amounts of DHA and EPA in the fish oil group were more similar to the actual intake (Fig. 1).

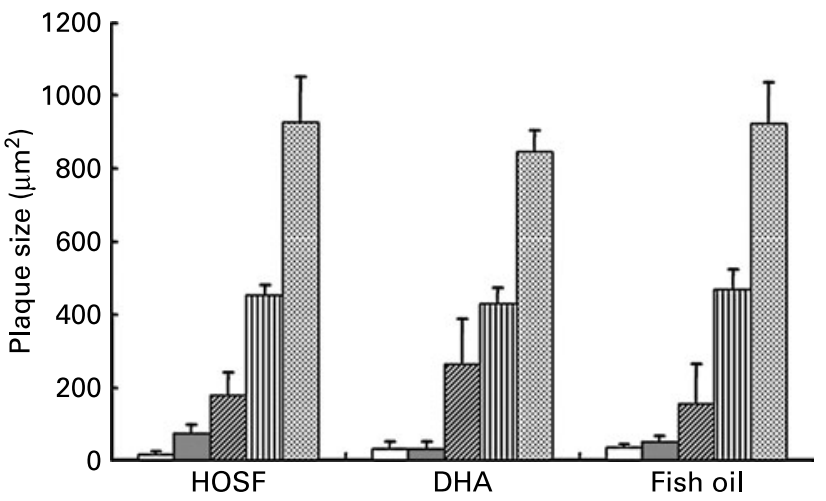

Fig. 3. Size of atherosclerotic plaque upon dietary intervention with $2 \%$ $(\mathrm{w} / \mathrm{w}) \mathrm{DHA}, 2 \%(\mathrm{w} / \mathrm{w})$ fish oil or $2 \%(\mathrm{w} / \mathrm{w})$ high-oleic sunflower-seed (HOSF) oil for $2 \mathrm{~d}(\square)$, 1 week (口), 2 weeks (国), 4 weeks (畂) and 10 weeks (回). Values are means for five animals per time point, with standard errors represented by vertical bars. Atherosclerotic plaque sizes at the aortic root were determined as described in the Materials and methods section.

After $2 \mathrm{~d}$ and 10 weeks of intervention with DHA, as compared with HOSF oil, a small increase in hepatic EPA incorporation was apparent, despite the lack of EPA in the DHA (and HOSF oil) diet. This may indicate retroconversion of EPA from DHA in the liver. This retroconversion occurs especially in EPA-depleted conditions ${ }^{(25)}$ such as those present in the DHA (and HOSF oil) group. The lower levels of EPA could be also explained by the higher EPA requirement for production of eicosanoids, a process in which DHA is not substantially involved ${ }^{(26)}$, the larger oxidation of EPA in contrast to that of $\mathrm{DHA}^{(27)}$ and the elongation of EPA to docosapentaenoic $\operatorname{acid}^{(28)}$. A higher content of hepatic DHA compared with EPA upon fish oil supplementation also occurs in rats ${ }^{(29,30)}$ and human subjects ${ }^{(29,31)}$. Despite the obvious changes in hepatic fatty acid composition, we did not observe any changes in liver weight or in the total amount of hepatic fat caused by the DHA or fish oil diets during the 10-week intervention period. Previously, we and others observed a decrease in liver weight as well as a decrease in hepatic fat or hepatic TAG upon intervention with fish oil, albeit at higher doses $(60 \%$ energy and $3 \%$ $(w / w))^{(9,32)}$. A decrease in hepatic fat content may thus only occur upon intervention with relatively high doses of fish oil.

The effects of dietary fish oil on sEH protein levels in the liver appear to have a time-dependent pattern. In one of our previous studies, $3 \%(\mathrm{w} / \mathrm{w})$ dietary fish oil increased $\mathrm{sEH}$ protein after 3 weeks of intervention in apo $\mathrm{E}^{*} 3$-Leiden transgenic mice ${ }^{(9)}$. However, $3 \%(\mathrm{w} / \mathrm{w})$ dietary fish oil decreased hepatic levels of $\mathrm{sEH}$ protein in Apoe $e^{-1-}$ mice after 10 weeks of intervention compared with HOSF oil (B. de Roos, unpublished results), and $2 \%$ (w/w) dietary fish oil resulted in lower levels of hepatic sEH levels in Apoe $e^{-I-}$ mice with time compared with HOSF oil in the present study, as determined by proteomic analysis of hepatic protein homogenates $(P<0 \cdot 05$; Fig. 2(a) and Table 3$)$. These findings indicate that fish oil up-regulates hepatic $\mathrm{sEH}$ protein in the short term, but prevents the up-regulation of $\mathrm{sEH}$ as observed after intervention with DHA or HOSF oil upon long-term dietary exposure. The differential effects observed between the fish oil and the DHA groups, combined with the fact that in the DHA and fish oil groups hepatic DHA levels 
were relatively similar after 10 weeks, suggest that the regulatory effects of fish oil on hepatic sEH levels may be due to EPA alone. The reason for a time-dependent regulation of EPA on hepatic sEH protein levels is unclear, but may involve the slower incorporation of EPA in the liver as compared with DHA. Indeed, the proportion of EPA in the hepatic lipid component was almost four times higher in the long term (after 10 weeks of intervention) than in the short term (after $2 \mathrm{~d}$ of intervention) upon intervention with fish oil. In addition, the effects seem to be stronger with the higher doses of fish oil we used in previous studies $\left(3 \%\right.$, w/w) ${ }^{(9)}$ (B. de Roos, unpublished results) compared with a dose of $2 \%(\mathrm{w} / \mathrm{w})$ that was used in the present study. Furthermore, analysis of hepatic sEH protein levels at different points in time revealed a considerable rise in hepatic sEH levels in all three groups after 2 weeks of intervention (Fig. 2(a)). This trend may be partially explained by the ageing effect on sEH activity. Indeed, a previous study has reported significant increasing effects of ageing on $\mathrm{sEH}$ activity within a period of 4 weeks as well as a correlation between $\mathrm{sEH}$ activity and protein levels ${ }^{(33)}$. Proteomics analysis was able to detect changes in hepatic sEH protein levels, which Western blot analysis did not upon DHA or fish oil intervention. The apparent lack of differences in the Western blots may be explained by the fact that during Western blotting, proteins of low abundance co-migrate on the gel with more abundant proteins, which could limit the relative binding of low-abundant proteins due to a finite binding capacity to the membrane. The true amount of the low-abundant proteins is then not being reflected in the immunostaining experiment. Proteomics indeed offers the technological advantage that proteins are separated and identified both on the basis of their iso-electrophoretic and their molecular size properties, and most compelling the MS sequencing data. Expression of the $\mathrm{sEH}$ gene in the liver was unaffected by the longchain $n$-3 PUFA intervention in time. However, sEH appears to be constitutively expressed and regulation probably occurs at the post-transcriptional level ${ }^{(34)}$.

Intervention with DHA or fish oil caused differential regulation of hepatic proteins with time as assessed by proteomics (Table 3). For example, intervention with DHA caused both up- and down-regulation of different proteins with time. On the other hand, intervention with fish oil caused a general down-regulation of some proteins especially in the first week of the intervention (Table 3 ). Such a concerted downregulation of proteins upon fish oil intervention has also occurred in a previous study ${ }^{(9)}$. It is likely that the dynamic nature of some metabolic pathways and homeostatic mechanisms alter the effects that an intervention may have on protein levels, indicating that length of time plays a pivotal role. Therefore, effects of long-chain $n$-3 PUFA on hepatic protein levels identified in the short term may not be representative of the longer-term effects, emphasising the advantage of a time-course design to elucidate effects of nutritional interventions.

Both DHA and fish oil interventions caused a downregulation of hepatic apoA1 with time (Table 3), suggesting that both DHA and EPA are equally active in the regulation of this protein. Fish oil intervention significantly decreased levels of one positional variant of serum apoA1, the major protein component of HDL, decreased the amount of the smaller $\mathrm{HDL}_{3 \mathrm{a}}$ and $\mathrm{HDL}_{3 \mathrm{~b}}$ particles, and increased amounts of the larger, more cholesterol-rich $\mathrm{HDL}_{2 \mathrm{a}}$ particles ${ }^{(21)}$. Increased HDL particle size is thought to serve as a marker for more efficient reverse cholesterol transport and lower CHD risk in humans ${ }^{(35)}$. The fact that fish oil supplementation only appears to affect protein levels of one positional variant of apoA1, whereas levels of other positional variants of apoA1 remain unaffected in the present and another study ${ }^{(21)}$, may explain why fish oil supplementation may not necessarily change overall serum levels of apoA $1^{(21,36-38)}$.

Both dietary DHA and fish oil caused a down-regulation of hepatic peroxiredoxin 3 with time (Table 3). Peroxiredoxin 3 is involved in elimination of peroxides generated during metabolism and may also moderate the signalling cascade of growth factors and TNF- $\alpha$ by regulating the intracellular concentrations of $\mathrm{H}_{2} \mathrm{O}_{2}{ }^{(39)}$. Oxidative stress is strongly associated with atherogenesis by inducing inflammatory mediators (for example, cytokines and adhesion molecules) through activation of $\mathrm{NF}-\mathrm{KB}^{(40)}$; therefore, down-regulation of peroxiredoxin 3 by both DHA and fish oil may indicate lower levels of ongoing inflammatory processes in the long-chain $n$-3 PUFA groups. In human cardiac fibroblasts, peroxiredoxin 3 gene expression was found to be mediated by the forkhead box transcription factor FOXO3a ${ }^{(16)}$, which in human umbilical vein endothelial cells is inactivated by $11,12-\mathrm{EET}^{(17)}$. Therefore, dietary fish oil may inhibit $\mathrm{sEH}$ leading to increased availability of EET, which in turn could inactivate FOXO3a, resulting in lower levels of peroxiredoxin 3. Such regulation may represent a novel pathway in which dietary fish oil inhibits the inflammatory response. There is down-regulation of $\mathrm{sEH}$ protein levels in the liver of a mouse model with a disrupted IL-1 receptor (this compromises macrophage function and innate immune response) compared with $\mathrm{C} 57 \mathrm{Bl} / 6 \mathrm{~J}$ on a high-fat $\operatorname{diet}^{(41)}$, supporting the hypothesis that $\mathrm{sEH}$ protein levels and the inflammatory response are related. However, in the present study, hepatic gene expression of FOXO3a was unaffected by DHA or fish oil, as were hepatic protein levels of the antioxidant enzymes mitochondrial superoxide dismutase and catalase, which can also be regulated via FOXO3a ${ }^{(23,42)}$. This suggests that the decrease in peroxiredoxin 3 by the fish oil and DHA interventions, as compared with the HOSF oil intervention, is independent of FOXO3a gene expression. However, gene expression of FOXO3a may be unrelated to its activity, which was found to be affected by EET ${ }^{(17)}$.

EET have been shown to inhibit vascular smooth muscle migration, decrease inflammation, inhibit platelet aggregation and decrease adhesion molecule expression, therefore representing an endogenous protective mechanism against atherosclerosis $^{(43)}$. If fish oil or EPA were to affect levels of EET via modulation of $\mathrm{sEH}$, they may subsequently affect the development of atherosclerosis. However, in the present study both DHA and fish oil did not differentially affect atherosclerotic plaque size development in the aortic root as compared with HOSF oil during 10 weeks of intervention (Fig. 3). Our findings are in agreement with previous studies using $1 \%$ fish oil $^{(44,45)}$. Much higher doses of dietary fish oil, i.e. 5 and $20 \%$ (w/w), or $5 \%$ EPS, however, cause a small decrease in atherosclerosis development in these animal models ${ }^{(46-48)}$. However, these doses are very high and results from studies using more physiological doses of 
fish oil or EPA suggest that these fatty acids may not affect plaque size per se, but may affect the infiltration of inflammatory cells into plaques, thereby increasing plaque stability ${ }^{(6)}$.

In conclusion, both DHA and fish oil decreased hepatic protein levels of apoA1 and peroxiredoxin 3 with time, indicating that both treatments could beneficially affect lipoprotein metabolism and oxidative stress. This effect did not appear to be mediated by the transcription factor FOXO3a. Furthermore, intervention with DHA or fish oil resulted in a time-dependent regulation of the hepatic enzyme sEH. Especially after 4 weeks of intervention, fish oil but not DHA lowered protein levels of hepatic sEH compared with the HOSF oil control group. The lower levels of $\mathrm{sEH}$ in the fish oil group resulted from the prevention of an increase that occurred in the DHA and the HOSF oil control groups rather than a decrease in hepatic protein levels of sEH. The differential effects observed between the DHA and fish oil interventions suggest that EPA may be responsible for this effect. Lower levels of hepatic sEH protein could lead to locally increased levels of EET, which are associated with a decreased inflammatory response. Intervention with DHA or fish oil did not result in a decrease in plaque size development. However, modulation of hepatic sEH protein levels by fish oil may still be linked to other factors, such as infiltration of inflammatory cells into the atherosclerotic plaque contributing to plaque stabilisation.

\section{Acknowledgements}

The present study was funded by the Scottish Government Rural and Environment Research and Analysis Directorate (RERAD).

We thank Dr Bruce Hammock, University of California, for kindly providing the sEH antibody used in the present study, and Lipid Nutrition, The Netherlands, for kindly providing the Marinol ${ }^{\mathrm{TM}} \mathrm{C}-38$ oil. We also thank Dr Graham Horgan and Dr Claus Mayer from Biomathematics and Statistics Scotland (BIOSS) for their assistance with the statistical analysis.

Y. M. and B. dR. worked as investigators, conducted the data management and wrote the manuscript; Y. M., K. R., G. R., M. R., G. D. and M.-J. G. performed the analyses; F. T. and A. S. provided assistance with the study design and analysis.

The authors have no conflicts of interest.

The supplementary material for this article can be found at http://www.journals.cambridge.org/bjn

\section{References}

1. Kromhout D, Bosschieter EB \& de Lezenne CC (1985) The inverse relation between fish consumption and 20-year mortality from coronary heart disease. N Engl J Med 312, 1205-1209.

2. Hu FB \& Willett WC (2002) Optimal diets for prevention of coronary heart disease. JAMA 288, 2569-2578.

3. Hu FB, Bronner L, Willett WC, et al. (2002) Fish and omega-3 fatty acid intake and risk of coronary heart disease in women. JAMA 287, 1815-1821.

4. GISSI Investigators (1999) Dietary supplementation with $n-3$ polyunsaturated fatty acids and vitamin $\mathrm{E}$ after myocardial infarction: results of the GISSI-Prevenzione trial. Gruppo
Italiano per lo Studio della Sopravvivenza nell'Infarto miocardico. Lancet 354, 447-455.

5. de Roos B, Mercer DK, Wainwright C, et al. (2005) Effect of long chain n-3 PUFA on endothelial activation, endothelial function and atheromatous plaque stability. Curr Nutr Food Sci 1, 167-177.

6. Thies F, Garry JM, Yaqoob P, et al. (2003) Association of $n-3$ polyunsaturated fatty acids with stability of atherosclerotic plaques: a randomised controlled trial. Lancet 361, 477-485.

7. de Roos B, Mavrommatis Y \& Brouwer IA (2009) Longchain $n-3$ polyunsaturated fatty acids: new insights into mechanisms relating to inflammation and coronary heart disease. $\mathrm{Br} J$ Pharmacol (epublication ahead of print version 5 May 2009).

8. Mori TA \& Woodman RJ (2006) The independent effects of eicosapentaenoic acid and docosahexaenoic acid on cardiovascular risk factors in humans. Curr Opin Clin Nutr Metab Care 9, 95-104.

9. de Roos B, Duivenvoorden I, Rucklidge G, et al. (2005) Response of apolipoprotein $\mathrm{E}^{*} 3$-Leiden transgenic mice to dietary fatty acids: combining liver proteomics with physiological data. FASEB J 19, 813-815.

10. Spector AA \& Norris AW (2007) Action of epoxyeicosatrienoic acids on cellular function. Am J Physiol Cell Physiol 292, C996-C1012.

11. Node K, Huo Y, Ruan X, et al. (1999) Anti-inflammatory properties of cytochrome P450 epoxygenase-derived eicosanoids. Science 285, 1276-1279.

12. Fisslthaler B, Popp R, Kiss L, et al. (1999) Cytochrome P450 2C is an EDHF synthase in coronary arteries. Nature 401, 493-497.

13. Fisslthaler B, Fleming I \& Busse R (2000) EDHF: a cytochrome P450 metabolite in coronary arteries. Semin Perinatol 24, 15-19.

14. Ridker PM, Vaughan DE, Stampfer MJ, et al. (1993) Endogenous tissue-type plasminogen activator and risk of myocardial infarction. Lancet 341, 1165-1168.

15. Spector AA, Fang X, Snyder GD, et al. (2004) Epoxyeicosatrienoic acids (EETs): metabolism and biochemical function. Prog Lipid Res 43, 55-90.

16. Chiribau CB, Cheng L, Cucoranu IC, et al. (2008) FOXO3a regulates peroxiredoxin III expression in human cardiac fibroblasts. J Biol Chem 283, 8211-8217.

17. Potente M, Fisslthaler B, Busse R, et al. (2003) 11,12-Epoxyeicosatrienoic acid-induced inhibition of FOXO factors promotes endothelial proliferation by down-regulating p27Kip1. J Biol Chem 278, 29619-29625.

18. Folch J, Lees M \& Sloane Stanley GH (1957) A simple method for the isolation and purification of total lipides from animal tissues. J Biol Chem 226, 497-509.

19. Arbones-Mainar JM, Ross K, Rucklidge GJ, et al. (2007) Extra virgin olive oils increase hepatic fat accumulation and hepatic antioxidant protein levels in Apoe $e^{(-/-)}$mice. J Proteome Res 6, 4041-4054.

20. de Roos B, Rucklidge G, Reid M, et al. (2005) Divergent mechanisms of cis9, trans 11 -and trans 10 , cis 12 -conjugated linoleic acid affecting insulin resistance and inflammation in apolipoprotein E knockout mice: a proteomics approach. FASEB J 19, $1746-1748$.

21. de Roos B, Geelen A, Ross K, et al. (2008) Identification of potential serum biomarkers of inflammation and lipid modulation that are altered by fish oil supplementation in healthy volunteers. Proteomics 8, 1965-1974.

22. Paigen B, Morrow A, Holmes PA, et al. (1987) Quantitative assessment of atherosclerotic lesions in mice. Atherosclerosis 68, 231-240.

23. Kops GJ, Dansen TB, Polderman PE, et al. (2002) Forkhead transcription factor $\mathrm{FOXO}$ a protects quiescent cells from oxidative stress. Nature 419, 316-321. 
24. Nemoto S \& Finkel T (2002) Redox regulation of forkhead proteins through a p66shc-dependent signaling pathway. Science 295, 2450-2452.

25. Willumsen N, Vaagenes H, Lie O, et al. (1996) Eicosapentaenoic acid, but not docosahexaenoic acid, increases mitochondrial fatty acid oxidation and upregulates 2,4-dienoyl-CoA reductase gene expression in rats. Lipids 31, 579-592.

26. Zhou L \& Nilsson A (2001) Sources of eicosanoid precursor fatty acid pools in tissues. $J$ Lipid Res 42, 1521-1542.

27. Madsen L, Froyland L, Dyroy E, et al. (1998) Docosahexaenoic and eicosapentaenoic acids are differently metabolized in rat liver during mitochondria and peroxisome proliferation. $J$ Lipid Res 39, 583-593.

28. Hansen JB, Grimsgaard S, Nilsen H, et al. (1998) Effects of highly purified eicosapentaenoic acid and docosahexaenoic acid on fatty acid absorption, incorporation into serum phospholipids and postprandial triglyceridemia. Lipids $\mathbf{3 3}$, $131-138$

29. Brossard N, Croset M, Pachiaudi C, et al. (1996) Retroconversion and metabolism of $\left[{ }^{13} \mathrm{C}\right] 22: 6 n-3$ in humans and rats after intake of a single dose of $\left[{ }^{13} \mathrm{C}\right] 22: 6 n$-3-triacylglycerols. $A m J$ Clin Nutr 64, 577-586.

30. Morgado N, Rigotti A \& Valenzuela A (2005) Comparative effect of fish oil feeding and other dietary fatty acids on plasma lipoproteins, biliary lipids, and hepatic expression of proteins involved in reverse cholesterol transport in the rat. Ann Nutr Metab 49, 397-406.

31. Thies F, Nebe-von-Caron G, Powell JR, et al. (2001) Dietary supplementation with eicosapentaenoic acid, but not with other long-chain $n-3$ or $n-6$ polyunsaturated fatty acids, decreases natural killer cell activity in healthy subjects aged $>55$ y. Am J Clin Nutr 73, 539-548.

32. Kim HJ, Takahashi M \& Ezaki O (1999) Fish oil feeding decreases mature sterol regulatory element-binding protein 1 (SREBP-1) by down-regulation of SREBP-1c mRNA in mouse liver. A possible mechanism for down-regulation of lipogenic enzyme mRNAs. J Biol Chem 274, 25892-25898.

33. Pinot F, Grant DF, Spearow JL, et al. (1995) Differential regulation of soluble epoxide hydrolase by clofibrate and sexual hormones in the liver and kidneys of mice. Biochem Pharmacol 50, 501-508.

34. Newman JW, Morisseau C \& Hammock BD (2005) Epoxide hydrolases: their roles and interactions with lipid metabolism. Prog Lipid Res 44, 1-51.

35. Alagona C, Soro A, Ylitalo K, et al. (2002) A low high density lipoprotein (HDL) level is associated with carotid artery intima-media thickness in asymptomatic members of low HDL families. Atherosclerosis 165, 309-316.

36. Buckley R, Shewring B, Turner R, et al. (2004) Circulating triacylglycerol and apoE levels in response to EPA and docosahexaenoic acid supplementation in adult human subjects. $\mathrm{Br}$ J Nutr 92, 477-483.

37. Williams CM, Moore F, Morgan L, et al. (1992) Effects of $n-3$ fatty acids on postprandial triacylglycerol and hormone concentrations in normal subjects. Br J Nutr 68, 655-666.

38. Caslake MJ, Miles EA, Kofler BM, et al. (2008) Effect of sex and genotype on cardiovascular biomarker response to fish oils: the FINGEN Study. Am J Clin Nutr 88, 618-629.

39. Fujii J \& Ikeda Y (2002) Advances in our understanding of peroxiredoxin, a multifunctional, mammalian redox protein. Redox Rep 7, 123-130.

40. Wang T, Zhang X \& Li JJ (2002) The role of NF-кB in the regulation of cell stress responses. Int Immunopharmacol $\mathbf{2}$, $1509-1520$.

41. de Roos B, Rungapamestry V, Ross K, et al. (2009) Attenuation of inflammation and cellular stress related pathways maintains insulin sensitivity in obese type I interleukin 1 receptor knockout $\left(\mathrm{IL}_{\mathrm{RI}}{ }^{-/-}\right.$) mice on a high-fat diet. Proteomics 9, 3244-3256.

42. Nemoto S, Combs CA, French S, et al. (2006) The mammalian longevity-associated gene product p66shc regulates mitochondrial metabolism. J Biol Chem 281, 10555-10560.

43. Larsen BT, Gutterman DD \& Hatoum OA (2006) Emerging role of epoxyeicosatrienoic acids in coronary vascular function. Eur J Clin Invest 36, 293-300.

44. Zampolli A, Bysted A, Leth T, et al. (2006) Contrasting effect of fish oil supplementation on the development of atherosclerosis in murine models. Atherosclerosis 184, 78-85.

45. Xu Z, Riediger N, Innis S, et al. (2007) Fish oil significantly alters fatty acid profiles in various lipid fractions but not atherogenesis in apo E-KO mice. Eur J Nutr 46, 103-110.

46. Wang HH, Hung TM, We J, et al. (2004) Fish oil increases antioxidant enzyme activities in macrophages and reduces atherosclerotic lesions in apoE-knockout mice. Cardiovasc Res 61, 169-176.

47. Casós K, Sáiz MP, Ruiz-Sanz JI, et al. (2008) Atherosclerosis prevention by a fish oil-rich diet in apoE $\mathrm{E}^{(-/-)}$mice is associated with a reduction of endothelial adhesion molecules. Atherosclerosis 201, 306-317.

48. Matsumoto M, Sata M, Fukuda D, et al. (2008) Orally administered eicosapentaenoic acid reduces and stabilizes atherosclerotic lesions in apoE-deficient mice. Atherosclerosis 197, 524-533. 